\title{
Assessment of a Network Infrastructure: A Basis for New Network Topology Proposal
}

\author{
Angelo P. Asignacion, Marvin O. Mallari, Reynaldo Gomez, Jr., Michael John M. Villar, Ryan \\ John L. De Lara
}

\begin{abstract}
Colegio de Sebastian (CDS), being a young academic and business entity, is in the process of developing its operations to serve its clients' satisfaction. This means that it must adapt itself to changes and improvements to survive the tough competition of private institutions. Effective communication in any business is a vital consideration that an owner must prioritize. Most growing businesses today are inclined to the use of technology to enhance the effectivity of their communication, and this entails the structuring of their computer network. In line with this, an assessment of the current network infrastructure was done at CDS to determine the need for new network topology. Through conducted surveys, CDS' network infrastructure was found out to have problems in terms of its topology that stems out to some issues like connectivity intermittence. To be able to provide a solution to such problem, a VLAN-based topology was proposed that includes topology that aims to achieve the four characteristics of good network architecture which are fault tolerance, scalability, quality of service and security. This research effort is to emphasize that properly planning an institution's network infrastructure is essential to serve its purpose optimally.
\end{abstract}

Keywords: computer networks, VLAN, ANOVA, network topology, network architecture.

\section{INTRODUCTION}

Communication can be characterized as the sharing of information, thought and feeling among people; consequently, communication is necessary for societal development and welfare [1]. Being this important, achieving an effective way of communicating must be a priority. Communication success is an important aspect of civil proliferation, whether it is at the interpersonal, intergroup, intragroup, organizational, or external levels [2].

Revised Manuscript Received on December 30, 2019.

* Correspondence Author

Angelo P. Asignacion., College of Engineering Department, AMA University, Quezon City, Philippines. Email: angeloasignacion@gmail.com Reynaldo H. Gomez Jr., Electrical Engineering Department, Don Honorio Ventura State University, Bacolor, Pampanga, Philippines. Email: iieered17@yahoo.com.ph

Marvin O. Mallari., College Of Engineering Department, Holy Cross College, Sta. Ana, Pampanga, Philippines. Email: mallari_marvin_o@yahoo.com

Michael John M. Villar., Graduate School Department, Nueva Ecija University of Science and Technology, Cabanatuan, Nueva Ecija, Philippines. Email: mjmvillar9@gmail.com

Ryan John L. De Lara., Graduate School Department, Nueva Ecija University of Science and Technology, Cabanatuan, Nueva Ecija, Philippines. Email: ryanjohn_delara@yahoo.com

(c) The Authors. Published by Blue Eyes Intelligence Engineering and Sciences Publication (BEIESP). This is an open access article under the CC BY-NC-ND license (http://creativecommons.org/licenses/by-nc-nd/4.0/)
Communication plays a critical role in an organization. It is said to be the life-wire of the organization. Nothing in the universe, human or otherwise that does not communicate; though the means of communication may vary. Communication is very crucial and unavoidable since people have intentions which they want to convey to another person, group or even to the outside world [3].

Moreover, effective communication is vital to all businesses. When customers contact a business, they expect prompt responses and satisfying experiences. Communications networks and applications play a vital role in that experience. If they do not work smoothly, the cost of serving customers increases and the company's image will be at risk. Thus, well-planned network topologies are important businesses sustainability, both large and small. It has the function to interconnect employees, support technical aspects of the business and manage resources. To be able to meet the requirements of businesses, computer networks are becoming more complex [4]. Also, the significance of technology in modern classroom learning cannot be ignored. It has school wireless design enabled students to learn more effectively by providing a wide range of learning materials that are accessible through the internet. Besides, on-campus intranets have greatly improved communication and interaction between students and teachers [5]. It simplifies knowledge acquisition, thereby improving the education system. For this reason, school wireless network design should respond to this need, and consists only of the necessary features and components to achieve maximum benefits.

Furthermore, it is right to say that good network design can save a great deal of money since the system will be kept up and running (availability) without having to stop activities when interruptions happen [6]. Manageability of the network will also lessen the need for outsourcing personnel that will attend to network's dilemma; thus, lowers maintenance cost potentially [7]. In recent years, when information technology (IT) revolution is exponentially growing, the paper-based manual system for processing information tend to be wasteful and bulky, thereby making computer-based technology overtake most office functions and procedures [8]. To support the maximum potential of such technology, an excellent interconnection or "networking" of devices should be planned and designed. For a growing institution like Colegio de Sebastian, the idea will help a lot. Colegio de Sebastian (CDS) is a non-sectarian, non-stock, non-profit corporation that was founded by a couple of who are known as philanthropists and educators on January 20, 2011, to promote service to the community. Its primary purpose is to offer affordable and accessible quality education at the tertiary level, the couple's dream for young people of Pampanga. 
The initial programs in the School of Business and Accountancy are Bachelor of Science in Accountancy, Bachelor of Science in Accounting Technology, and Bachelor of Science in Business Administration with majors in Financial Management and Human Resource Development Management. The first program in the School of Arts and Sciences is the Bachelor of Science in Psychology and the School of Hospitality Management, Bachelor of Science in Hotel and Restaurant Management. Furthermore, it is an institution of learning which commits itself to the quest for truth; cultivation, development, and propagation of knowledge in the arts, sciences and entrepreneurship and the enrichment of culture and care for creation through the use of reason illumined by courage and faith. As a growing institution, its need for technological support will be more apparent as years will pass by. Considering this, the proponent suggests the need for a better network design for Colegio de Sebastian. This effort aims to provide a starting point for the institution to have a network that is fault-tolerant, scalable, quality-assured and secured.

\section{METHODOLOGY}

\section{A. Data Collection}

The data necessary to perform this research are the current network topology and the current population of CDS. The details of the current network topology were obtained from MIS (Management information systems) Department, and the population respondents were obtained from the Registrar Department.

\section{B. Research Instruments}

The researcher had used data analysis toolpack of Microsoft Excel 2013 for statistical treatment and Packet Tracer 6.0.1 to illustrate the network topologies.

\section{Current Network Topology}

The details of current network topology were illustrated in Figure 1 to highlight some issues that are presented in this research. As what the figure shows, the first floor has two switches mainly for the Library and the Faculty. But it is noticeable in the topology that some of the Admin terminals (Guidance and Admission Office, Office of Student Affairs and VP for Academics) are connected in the Library-switch instead in the Admin-switch just because they have closer proximity to the Library-switch. Also, switches 3 and 4 on the third floors that are connected in the switch in the second floor (Admin switch) which poses some issues during peak hours.

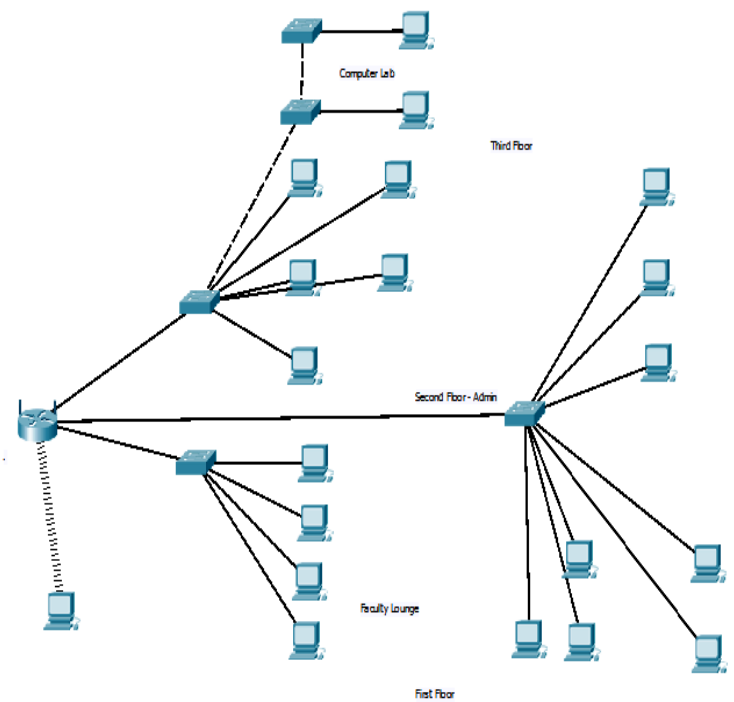

Figure 1 Topology Design of the Current Network of CDS

This kind of design will give rise to some problems. The performance of the network will suffer whenever most terminals are working because the router will handle all the operations at once. This design will cause bottleneck traffics that will lead to intermittent connection afterwards.

\section{Perceived Importance and Experience Regarding CDS Network Connectivity of Respondents}

To be able to establish the importance of having good network connectivity in an institution, perception of CDS population (students, faculty members and administrators) was solicited.

Table 1 presents the rating scale that was used to evaluate the importance of network connectivity within CDS.

Table 1 Rating Scale for Importance of Network Connectivity

\begin{tabular}{|c|c|c|}
\hline Mean Value & Weight & Verbal interpretation \\
\hline $4.20-5.00$ & 5 & Most Important (MI) \\
\hline $3.40-4.19$ & 4 & Very Important (VI) \\
\hline $2.60-3.39$ & 3 & Important (I) \\
\hline $1.80-2.59$ & 2 & Slightly Important (SI) \\
\hline $1.00-1.79$ & 1 & Not Important (NI) \\
\hline
\end{tabular}

Table 2 presents a summary of the perception of the respondents regarding the importance of network connectivity in an institution. The respondents observably agreed that network connectivity has a great contribution to learning and growth, social interaction and entertainment.

Table 2 Survey Result on the Respondents about the Importance of Network Connectivity

\begin{tabular}{|l|r|r|r|}
\hline Importance of Good Network Connectivity & \multicolumn{1}{|c|}{ Students } & Faculty & Admin \\
\hline Contribution to your learning and growth & 4.788043 & 4.767442 & 4.625 \\
\hline Social interaction & 4.402174 & 4.395349 & 4.375 \\
\hline Entertainment & 4.11413 & 3.604651 & 3.5625 \\
\hline Job Seeking & 2.445652 & 2.745098 & 2.375 \\
\hline Others & 2.603261 & 2.55814 & 2.75 \\
\hline
\end{tabular}

Another factor that is assessed is the overall experience of CDS personnel about network connectivity. Table 3 will interpret the mean value of the survey results that will be used in concluding the overall experience of respondents regarding the network connectivity of the respondents. Findings in this part of the study will also later be used as a basis for the development of the networking plan.

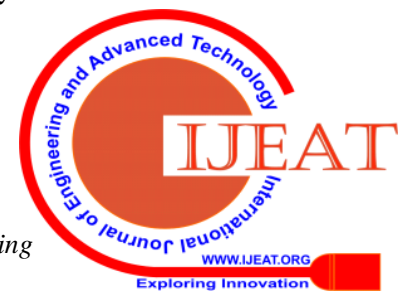


Table 3 Rating Scale for the Experience of CDS Personnel about Network Connectivity

\begin{tabular}{|c|c|c|}
\hline Mean Value & Weight & Verbal interpretation \\
\hline $4.20-5.00$ & 5 & Outstanding $(0)$ \\
\hline $3.40-4.19$ & 4 & Very Satisfactory (VS) \\
\hline $2.60-3.39$ & 3 & Satisfactory (S) \\
\hline $1.80-2.59$ & 2 & Needs Improvement (NI) \\
\hline $1.00-1.79$ & 1 & Poor $(\mathrm{P})$ \\
\hline
\end{tabular}

Table 4 presents a summary of the perception of the respondents regarding their experience regarding network connectivity in the institution. The respondents were asked about their experience about their network usage like the consistency of connectivity, online video buffering, picture upload and download etc.. The respondents observably agreed that network connectivity is poor and needs improvement.

Table 4 Survey Result on the Respondents about their Experience about Network Connectivity

\begin{tabular}{|c|r|r|r|}
\hline Experienced Network Connectivity & \multicolumn{1}{c|}{ Students } & \multicolumn{1}{c|}{ Faculty } & \multicolumn{1}{c|}{ Admin } \\
\hline Consistency of Connectivity & 2.304348 & 1.883721 & 2.0625 \\
\hline Video Buffering of Online Streaming & 1.880435 & 2.627907 & 2.0625 \\
\hline Downloading of picture & 2.622222 & 2.697674 & 2.9375 \\
\hline Uploading of picture & 3.13587 & 2.186047 & 2.4375 \\
\hline Downloading of file & 3.559783 & 3.45283 & 2.875 \\
\hline Uploading of file & 2.62987 & 2.604651 & 2.4375 \\
\hline Downloading of music & 2.974576 & 2.511628 & 2.375 \\
\hline Uploading of music & 2.597826 & 2.55814 & 2.777778 \\
\hline Downloading of video & 1.972826 & 2.666667 & 1.75 \\
\hline Uploading of video & 1.891304 & 1.930233 & 2 \\
\hline Email Accessing & 2.784091 & 3.232558 & 2.75 \\
\hline Chat and short messaging & 2.63587 & 2.738095 & 2.3125 \\
\hline
\end{tabular}

\section{RESULTS \& DISCUSSION}

\section{A. Descriptive Statistics and Inferential Results}

To be able to arrive at a reliable decision if CDS needs a better network topology, survey about the perception of users (students, faculty members and administrators) in the importance and their experience regarding the network connectivity was conducted. After gathering the survey results, ANOVA (Analysis of Variance) was employed. This is to analyze that the respondents agree that network connectivity is important and the current network infrastructure needs some improvements.

Table 5 shows the analysis for the importance of Network Connectivity of the surveyed groups using ANOVA by Excel Spreadsheet. Because the value of $\mathrm{F} \leq \mathrm{F}_{\text {crit }}$ $(0.021808 \leq 3.885294)$, the null hypothesis is accepted, that is, there is no significant difference on the perception of the different group of respondents as to the importance of the network connectivity on various areas. It is inferable that the respondents perceive network connectivity is important.

Table 5 Descriptive and Inferential Statistics Result (Importance)

\begin{tabular}{|c|c|c|c|c|}
\hline \multicolumn{5}{|l|}{ Descriptive } \\
\hline Groups & Items & Sum & Average & Variance \\
\hline Students & 5 & 18.35326 & 3.670652 & 1.155077 \\
\hline Faculty & 5 & 18.07068 & 3.614136 & 0.952713 \\
\hline Administrators & 5 & 17.6875 & 3.5375 & 0.964063 \\
\hline \multicolumn{5}{|l|}{ Inferential } \\
\hline Source of Variation & $\mathrm{df}$ & $\mathrm{F}$ & P-value & F crit \\
\hline Between Groups & 2 & 0.021808 & 0.978467 & 3.885294 \\
\hline Within Groups & 12 & & & \\
\hline Total & 14 & & & \\
\hline
\end{tabular}

Table 6 shows the following analysis for the importance of Network Connectivity to the surveyed groups. Because the value of $\mathrm{F} \leq$ Fcrit $(0.692059 \leq 3.284918)$, the null hypothesis is accepted, that is, there is no significant difference on the perception of the different group of respondents as to their experience about the network connectivity on various areas. It is inferable that the respondents have the same perception that the current network connectivity of the institution is poor and need some improvements.

Table 6 Descriptive Statistics and Inferential Result (Experience)

\begin{tabular}{|c|c|c|c|c|}
\hline \multicolumn{5}{|l|}{ Descriptive } \\
\hline Groups & Items & Sum & Average & Variance \\
\hline Students & 12 & 30.98902 & 2.582418 & 0.262026 \\
\hline Faculty & 12 & 31.09015 & 2.590846 & 0.209351 \\
\hline Administrators & 12 & 28.77778 & 2.398148 & 0.145556 \\
\hline \multicolumn{5}{|l|}{ Inferential } \\
\hline Source of Variation & $\mathrm{df}$ & $\mathrm{F}$ & P-value & F crit \\
\hline Between Groups & 2 & 0.692059 & 0.507662 & 3.284918 \\
\hline Within Groups & 33 & & & \\
\hline Total & 35 & & & \\
\hline
\end{tabular}

\section{B. Proposed Topology}

As suggested by the descriptive statistics and inferential results, CDS needs a better network plan that will cater to its connectivity needs.

Figure 2 is the proposed network design for CDS that aims to cater to the institutions academic and business needs. The implementation of this proposed topology utilizes the advantages of Virtual Local Area Network concepts.

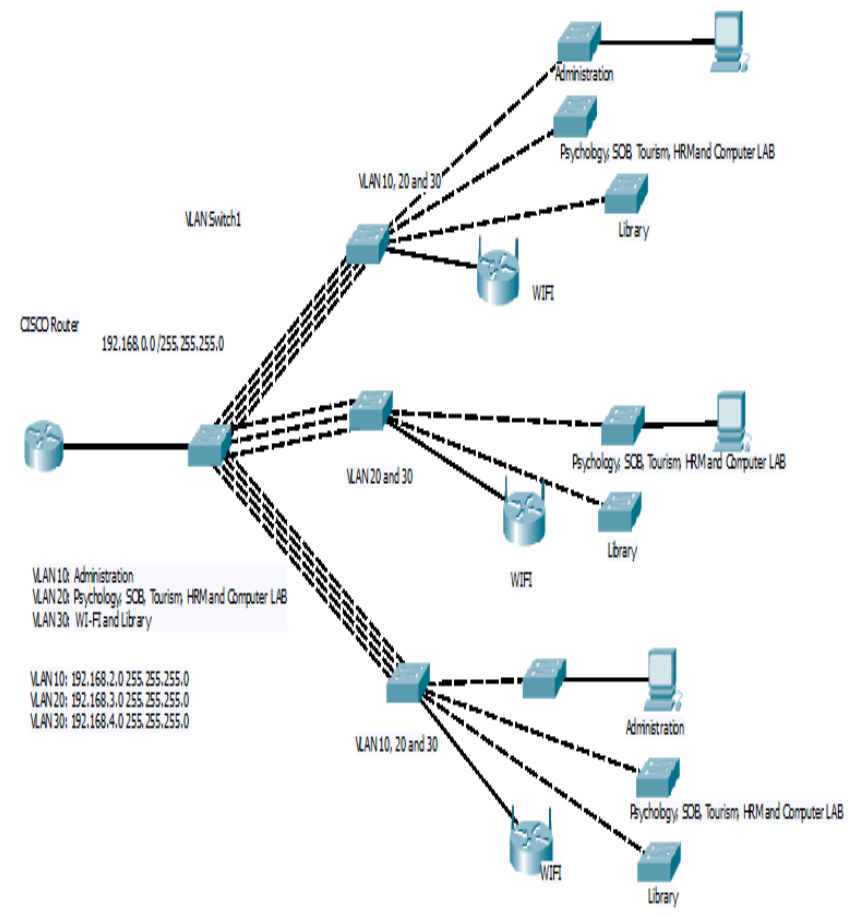

Figure 2 Proposed Network Topology

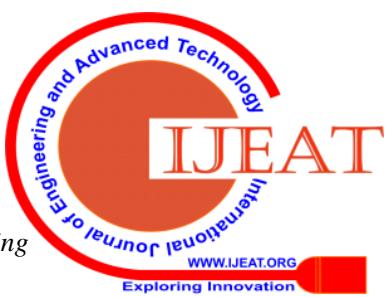


Assessment of a Network Infrastructure: A Basis for New Network Topology Proposal

The proposed topology will make use of three VLANs. Table 7 indicates the three VLANs that will support the population of the institution.

Table 7 VLAN Names and Users

\begin{tabular}{|c|c|}
\hline VLAN Name & User Group \\
\hline VLAN 10 & Administration \\
\hline VLAN 20 & $\begin{array}{c}\text { Psychology, SOB, Tourism, HRM and } \\
\text { Computer Laboratory }\end{array}$ \\
\hline VLAN 30 & Students' WIFI and Library \\
\hline
\end{tabular}

The three VLANs can be categorized into three primary user groups: Administrators, Faculty members and the student population. As Figure 4 illustrated, the proposed topology includes one router, four managed switches, eight unmanaged switches and three wireless access. The managed switches will be deployed to increase bandwidth and make the network more fault-tolerant by using link aggregation capability of these switches.

The guidelines of the study in formulating the proposed topology are the four characteristics of good network architecture, namely fault tolerance, scalability, quality of service and security. The achievement of the solution is summarized as follows:

\section{Fault Tolerance}

Availability of the network at all times is one of the main concerns that this study wants to address. Analyzing the solution that the researchers provided, VLAN switches usage make the network fault-tolerant by the usage of manageable switches that have link aggregation features. In this way, the connectivity of the network is always assured.

\section{Scalability}

The proposed network topology will be able to support the growing need of CDS for interconnection by the use of VLAN concept. The use of manageable switches will enable the network to be scalable by configuring VLANs according to demand.

To be able to determine the maximum possible users that the topology can accommodate, the researchers considered the ports per switches and the distributable IP addresses for WIFI connection.

The computation is done following the hierarchical internetworking model namely, core distribution and access levels. Table 8 summarizes the computation number of possible wired and wireless connection of the proposed topology.

\section{Table 8 Computation of Number of Possible Wired and Wireless Connection of the Proposed Topology}

\begin{tabular}{|c|c|c|c|c|c|c|c|}
\hline \multicolumn{8}{|c|}{ CORE } \\
\hline Cisco Router & Core Switches & $\begin{array}{c}\text { Available } \\
\text { Ports }\end{array}$ & Total Ports & $\begin{array}{l}\text { Ports Connecting } \\
\text { to Router }\end{array}$ & $\begin{array}{l}\text { Ports } \\
\text { Assigned } \\
\text { to VLAN } \\
\text { Trunks }\end{array}$ & Used Ports & $\begin{array}{c}\text { Unused } \\
\text { Ports }\end{array}$ \\
\hline 2 LAN Ports & 1 & 28 & 28 & 1 & 11 & 11 & 17 \\
\hline & & & & & & & \\
\hline & & & & & & & \\
\hline \multicolumn{8}{|c|}{ DISTRIBUTION } \\
\hline $\begin{array}{l}\text { Distribution } \\
\text { Switches }\end{array}$ & $\begin{array}{l}\text { Available } \\
\text { Ports }\end{array}$ & $\begin{array}{l}\text { Total } \\
\text { Ports }\end{array}$ & $\begin{array}{c}\text { Ports } \\
\text { Connecting } \\
\text { to Core } \\
\end{array}$ & $\begin{array}{l}\text { Remaining Ports to } 0 \\
\text { be Distributed to } \\
\text { VLANS }\end{array}$ & $\begin{array}{l}\text { No. of } \\
\text { VLAN's }\end{array}$ & $\begin{array}{l}\text { Ports Per } \\
\text { vLAN }\end{array}$ & \\
\hline 3 & 24 & 72 & 11 & 61 & 3 & 20 & \\
\hline \multicolumn{8}{|c|}{ FIRST LEVEL ACCESS } \\
\hline Access Switches & $\begin{array}{l}\text { Available } \\
\text { Ports }\end{array}$ & $\begin{array}{l}\text { Total } \\
\text { Ports }\end{array}$ & $\begin{array}{c}\text { Ports } \\
\text { Connecting } \\
\text { to } \\
\text { Distribution }\end{array}$ & $\begin{array}{l}\text { Remaining Ports to } \\
\text { be Assigns for } \\
\text { Users }\end{array}$ & & & \\
\hline 61 & 24 & 1464 & 61 & 1403 & & & \\
\hline Wireless & $\begin{array}{l}\text { Distributable } \\
\text { IP Address }\end{array}$ & $\begin{array}{l}\text { Total } \\
\text { WIFI } \\
\text { User }\end{array}$ & & & & & \\
\hline & 253 & 759 & & & & & \\
\hline
\end{tabular}

\section{Quality of Service}

Consistency of the network's connectivity during usage will mean that the performance of the network is optimum. For any academic or business purpose, users must experience quality service for they deserve to receive such. The designed topology using VLAN concept will segment the network into smaller groups in which only those users that should be interconnected will be grouped (eg. Admin People). Because of this, broadcasts of one group will not affect other groups or VLANs. Therefore, traffic will be reduced as each broadcast will be received by relevant VLAN only. This will mean that bottlenecks will be prevented from occurring, making the network to provide quality service.

\section{Security}

Protection of users, especially Admin people and Faculty members, against malicious users is one of the most important attributes of a network. With the use of VLAN concept, the security of the network is enhanced because the administrator of the network will have the control over the traffic over the network; therefore, illegal access of sensitive information will be prevented by proper VLAN set-up.

\section{CONCLUSION}

Communication among people brings forth opportunities for them to exchange knowledge, build civilizations and improve the way of life. Effective means of communication would signify a greater chance of success for them as beings. With this, formations of governments, schools, hospitals, businesses and other organizations became handy. Colegio de Sebastian (CDS), being a learning institution as well as a business entity, must provide itself with a good communication system for the welfare of its clientele. This study's effort is to fulfil that goal. To be able to establish the need for a new topology, a survey about the importance and experience of network connectivity was conducted, and ANOVA (Analysis of Variance) was used as a statistical tool. Finally, a topology was proposed to satisfy the four characteristics of good network architecture (fault tolerance, scalability, quality service and security) using the concept of Virtual Local Area Network or VLAN. This solution aims to improve the overall experience of the network users and also ensure that the network will serve its purpose reliable for a long time.

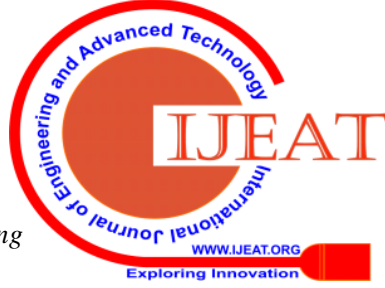




\section{RECOMMENDATIONS}

Future researchers may focus on the following recommendations:

1. The structured cabling plan can also be proposed that corresponds to the topology.

2. The central concept of the proposed topology is the usage of VLAN (Virtual Local Area Network) concept. Therefore, knowledge about proper configuration and simulation of the plan will be necessary upon implementation.

3. Prioritization of device installation should also be considered base on population growth. This effort will make the topology implementation more feasible in terms of budget allocation.

\section{REFERENCES}

1. C. Boyaci and A. Aksu, "The Importance Of Communication Within Organizations: A Research On Two 5 Star Hotels In Antalya Region," ... Adm. ..., pp. 3-5, 2000

2. D. June and J. Axen, "The Importance of Effective Communication," What they Didn't Teach Acad., pp. 131-132, 2013.

3. Ŕ. Ânûm , "Importance of Communication in Society." Importance of Communications in Sports., pp. 51-57, 2017.

4. H. J. Yang, "Current status and needs of educational computer network system for secondary industrial arts education in Taiwan , Republic of China," 1991.

5. M. Greenberger, J. Aronofsky, J. L. McKenney, and W. F. Massy, "Computer and information networks," Science (80-. )., vol. 182, no. 4107, pp. 29-35, 1973.

6. Cisco Press, "Introducing Network Design Concepts," pp. 1-48, 2014

7. C. E. Caicedo and W. Cerroni, "Design of a computer networking laboratory for efficient manageability and effective teaching," Proc. Front. Educ. Conf. FIE, pp. 1-6, 2009.

8. S. Ganguly, "COMMUNICATION MEDIA, SYSTEMS AND STRATEGY,” pp. 141-154.

\section{AUTHORS PROFILE}

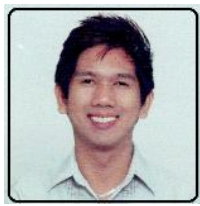

Angelo P. Asignacion is a Registered Electronics Engineer and Cisco Certified Network Associate. A faculty of College of Engineering in AMA University, Quezon City. He is a graduate of Master of Engineering Program Major in Electronics Engineering (MEP-EcE) at Bulacan State University (BSU) and currently pursuing his Doctor of Philosophy in Engineering Management (PhD. EnM) at Nueva Ecija University of Science and Technology (NEUST). Member of Institute of Electronics Engineers of the Philippines. His research works focuses mostly in computer networks, material science, and electrical power system monitoring and curriculum development.

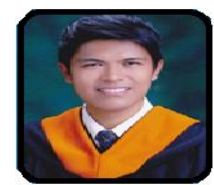

Marvin O. Mallari. Dean of the College of Engineering at Holy Cross College (Pampanga). A Graduate of Master of Science in Computer Engineering at Bulacan State University. Currently taking Ph.D. in Engineering Management at Nueva Ecija University of Science and Technology. And the Vice President for Education of the Institute of Computer Engineers of the Philippines (ICpEP) Region 3

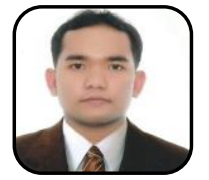

Reynaldo H. Gomez Jr. is a Registered Electrical Engineer, Registered Master Electrician and Licensed Professional Teacher. A faculty of Electrical Engineering Department of Don Honorio Ventura State University (DHVSU). He is a graduate of Master of Engineering Program Major in Electrical Engineering (MEP-EE) at Holy Angel University (HAU) and currently pursuing his Doctor of Philosophy in Engineering Management (PhD. EnM) at Nueva Ecija University of Science and Technology (NEUST). Member of Institute of Integrated Electrical Engineers. His research works focuses mostly in electrical power system monitoring, electrical distribution analysis, electrical system designing, power system protection and relaying.

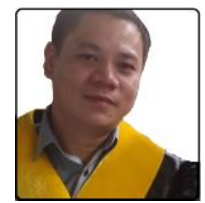

Michael John M. Villar is a Licensed Electrica Engineer from Nueva Ecija University of Science where he is an Associate Professor II at Nueva Ecija University of Science and Technology.

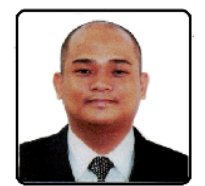

Ryan John L. De Lara A Licensed Electronics Engineer, Accredited Broadcaster, Certified Cable Tes Technician and Six Sigma Black Belt Certified. He is currently the Director for Research Development and Productivity Office and the former Dean of the College of Engineering and Computer Technology of Wesleyan University - Philippines Cushman Campus. He finished both his Masters and Doctor of Philosophy in Engineering Management at Nueva Ecija University of Science and Technology. The interim governor of the Institute of Electronics Engineers of the Philippines - Nueva Ecija Chapter (Accreditation No. 37). His research interest ranges from electronics system design, microcontroller application, energy system optimization, prototype development and electronics waste (e-waste) management. 